\title{
EDUCAÇÃO INCLUSIVA E A FORMAC̣ÃO DE PROFESSORES DE CIÊNCIAS: O PAPEL DAS UNIVERSIDADES FEDERAIS NA CAPACITAÇÃO DOS FUTUROS EDUCADORES
}

\author{
Mayara Lustosa Oliveira* \\ Adriana Maria Antunes** \\ Thiago Lopes Rocha*** \\ Simone Maria Teixeira****
}

RESUMO: A inclusão de alunos com necessidades educacionais especiais (NEE's) no sistema regular de ensino é hoje a diretriz principal das políticas públicas educacionais tanto a nível federal, quanto estadual e municipal. Entretanto, os licenciados egressos das instituições de Ensino Superior estão verdadeiramente preparados para o atendimento adequado aos portadores de NEE's? Foi no sentido de responder este questionamento que demos início ao desenvolvimento desta pesquisa, que analisou as opiniões de acadêmicos dos cursos de Física, Química e Biologia - Licenciaturas, do segundo e do último período de cada curso, a fim de observar qual o pensamento dos mesmos em relação à inclusão educacional e à ausência de disciplinas desta área nos cursos de licenciatura nas universidades públicas federais.

Palavras-chave: Educação Inclusiva, Licenciaturas, Currículo.

\section{INCLUSIVE EDUCATION AND SCIENCE TEACHER TRAINING: THE ROLE OF UNIVERSITIES IN THE PREPARATION OF FUTURE TEACHERS}

ABSTRACT: The inclusion of students with special educational needs (SEN) in the regular education system is today the main guideline for public policies on education at federal, state and municipal levels. However, are graduate students from higher education institutions actually prepared to provide adequate care for people with SEN? To answer this question we investigated the views of students in the second and last terms from Physics, Chemistry and Biology undergraduate programs to determine their perception on inclusive education and the lack of courses in the field in federal universities undergraduate programs.

Keywords: Inclusive Education, Undergraduate Programs, Curriculum.

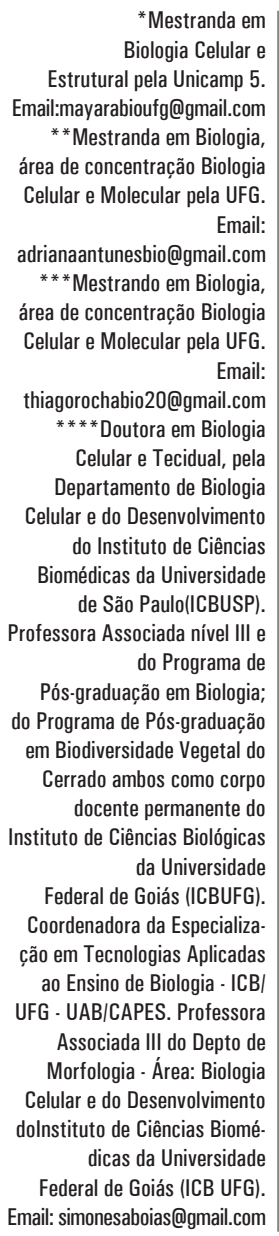




\section{INTRODUĈ̣̃O}

Nas últimas décadas, o ensino para alunos com necessidades educacionais especiais (NEE's), que tradicionalmente se pautava num modelo de atendimento especializado e segregado, tem se voltado para a chamada Educação Inclusiva (EI). Apesar de as propostas de inclusão escolar serem dominantes nos debates acerca de educação no Brasil, pouco se sabe sobre as características fundamentais da EI. Arnaiz afirma que a EI:

"É uma atitude, um sistema de valores, de crenças, não uma ação nem um conjunto de ações. Centra-se, pois, em como apoiar as qualidades, e, as necessidades de cada aluno e de todos os alunos na comunidade escolar, para que se sintam bem-vindos e seguros e alcancem êxitos" (1996, p. 27-28).

Intensificando a relevância da EI, Ainscow (2001, p. 293-294) a define como "Processo de incremento da participação dos alunos nas culturas, currículos e comunidades de suas escolas locais e da redução da sua exclusão dos mesmos". Dessa forma, a EI tem por objetivo aumentar a participação de todos os alunos no ambiente escolar e vem sendo proposta e discutida há tempos, porém poucas mudanças têm se efetivado.

Segundo Mantóan (2002),

"a inclusão escolar, sendo decorrente de uma educação acolhedora e para todos, propõe a fusão das modalidades de ensino especial e regular e a estruturação de uma nova modalidade educacional, consubstanciada na idéia de uma escola única. A pretensão é: unificar o que está fragmentado, dicotomizado, tratado isoladamente e oficializado em subsistemas paralelos, que mantém a discriminação dentro e fora das escolas; reconhecer as possibilidades humanas; e valorizar as 'eficiências desconhecidas' tão comumente rejeitadas e confundidas por não caberem nos moldes virtuais do "bom aluno"” $[\mathrm{s} / \mathrm{p}]$.

Em concordância com as ideias defendidas por Mantóan, a declaração de Salamanca, proposta a partir da conferência Mundial sobre necessidades educativas especiais, da UNESCO em 1994, assume que as escolas devem ajustar-se a todas as crianças, independentemente das suas condições físicas, sociais ou linguísticas. Nesse contexto, devem incluir crianças com deficiência ou superdotadas, crianças de minorias linguísticas, étnicas ou culturais e crianças de áreas ou grupos desfavorecidos ou marginais. A partir dessa conferência, a EI se transformou em proposta para as escolas de ensino regular, com o objetivo de combater as práticas discriminatórias e promover a inclusão dos deficientes na sociedade (SILVA et. al., 2004).

Segundo Croker e Kentish (1999), a intenção da legislação em benefício dos portadores de necessidades especiais, implica que estes possam ser inscritos na escola de sua comunidade local e receber uma educação adequada, com recursos apropriados, sendo esse ambiente o menos restritivo possível. 
Entretanto, sabe-se que, para haver efetiva consolidação do que exige a lei, são necessários alguns esforços e preparo por parte das unidades escolares e especialmente de seu corpo docente, já que estes vão lidar diretamente com alunos portadores de NEE's.

Dessa forma, cabe a reflexão a respeito da capacitação dos educadores, não só daqueles que já estão atuando, mas principalmente dos licenciandos, futuros professores que ainda estão em formação inicial. Para Figueiredo (2002), trabalhar com crianças especiais requer um aprimoramento do professor para que ele seja capaz de identificar as particularidades de seus alunos, visando eliminar as barreiras existentes em suas relações na escola. Portanto, é preciso preparar os professores para aceitarem as diferenças individuais das crianças e adolescentes portadores de alguma deficiência, incentivando-os a abandonar os tradicionais 'medos', a fim de enfrentar essa realidade cada vez mais presente no cotidiano escolar (CAVALCANTE, 2000).

Sacristán (1999) afirma que a formação de educadores é uma das pedras angulares imprescindíveis à renovação do sistema educativo. Nesse sentido, podemos perceber a necessidade de se buscar soluções desde a formação inicial dos professores, ou seja, capacitando os futuros educadores, nas universidades, em seus cursos específicos, para que estejam verdadeiramente aptos ao trabalho com estudantes portadores de NEE's. Para tanto, uma intervenção nos sistemas de ensino é imprescindível, no sentido de fazer cumprir as exigências da legislação vigente, proporcionando adaptações físicas, entre outros recursos, às instituições que recebem os portadores de NEE's. É necessário um esforço de conscientização da equipe escolar para a necessidade da inclusão de uma clientela que tem direito garantido pela Constituição, como todo cidadão, a educação gratuita de qualidade, dignidade enquanto pessoa humana e consciência de cidadania. (D’ANTINO, 1997).

Segundo Castanho e Freitas (2005, p.1), “a universidade é um lugar onde os valores e práticas de educação inclusiva precisam ser vivenciados" e para isso os acadêmicos necessitam de ensinamentos que vão além do conhecimento científico, além de conceitos e organização do trabalho pedagógico. São necessárias novas propostas como, por exemplo, a inserção de disciplinas que possam habilitar os educadores a realizar a transposição didática a todo o alunado, seja esse constituído de estudantes com NEE's ou não.

A vocação primária da universidade é o ensino, a formação de recursos humanos, e, no caso das faculdades ou departamentos de Educação, a formação de professores. Este é, sem dúvida, o aspecto determinante para a efetivação de uma política de inclusão educacional, a atuação direta na formação inicial de professores, visto que esses profissionais vão atuar diretamente com estudantes portadores de NEE's. Estudos como os de Bueno (1999), Glat (2000) e Glat et. al. (2003) têm demonstrado que a principal barreira para efetivação da EI é o despreparo dos professores para lidar com alunos com significativos déficits cognitivos, psicomotores e / ou sensoriais na complexidade cotidiana de uma classe regular. 
Tem-se a convicção de que o professor é uma peça essencial no conjunto que movimenta todo o sistema educacional. Sendo assim, é fundamental que o educador da escola regular seja devidamente capacitado para receber o novo alunado que está chegando à escola, pois “juntar crianças em uma sala de aula não lhes garante ensino, não lhes garante escola cumprindo seu papel, não lhes garante aprendizagem e, portanto, não lhes garante desenvolvimento" (PADILHA, 2004, p. 96). É preciso muito mais que isso.

Autores como Ainscow (2001), Padilha (2004) e Silva et. al. (2004) têm publicado trabalhos acerca da EI, porém poucos analisam o preparo oferecido aos futuros educadores nas universidades. A inclusão de alunos com NEE's no sistema regular de ensino é hoje a diretriz principal das políticas públicas educacionais, tanto a nível federal, quanto estadual e municipal (FERREIRA; GLAT, 2003). Entretanto, será que os licenciados que saem das instituições de Ensino Superior estão preparados para o atendimento adequado aos portadores de NEE's?

Estudos como os de Nóvoa (1992), Santos (1998) e Perrenoud (2000) têm proposto a formação continuada para que professores em exercício da profissão sejam capacitados a enfrentar as dificuldades que surgem dia-a-dia no ambiente escolar. Porém, se pensássemos na reestruturação de currículos dos cursos de licenciatura, e se o preparo para lidar com portadores de NEE's se iniciasse dentro da própria universidade, seria garantida a formação para todos e não apenas para parte dos professores do ensino regular, como ocorre na maioria dos casos na formação continuada. Somente assim as propostas de inclusão vão estar realmente inseridas no contexto educacional, e profissionais capacitados sairão das universidades viabilizando essa real inserção dos portadores de NEE's.

A partir do exposto, o presente estudo tem por objetivo analisar as opiniões e expectativas de graduandos dos cursos de Física, Química e Biologia (licenciatura), no que diz respeito ao preparo que os futuros educadores vêm recebendo nas universidades federais para lidar com alunos portadores de NEE's, além de discutir propostas de inserção de disciplinas que visem à socialização da educação inclusiva nos currículos das licenciaturas.

\section{METODOLOGIA}

\section{a) Apresentação do trabalho}

O presente trabalho trata-se de um estudo de cunho descritivo e exploratório, realizado por meio de análise e interpretação qualitativa e quantitativa de dados obtidos a partir da aplicação de um questionário sobre a temática abordada.

\section{b) Participantes}

As amostras analisadas foram obtidas de seis turmas de licenciandos dos cursos de: Ciências Biológicas, Química e Física da Universidade Federal de Goiás 
(UFG), sendo que os grupos avaliados foram compostos por duas turmas de cada curso: uma que acabou de ingressar na instituição e outra que está concluindo a graduação. Essa metodologia foi estabelecida a fim de comparar as visões e expectativas de ambos os perfis estudantis. Todos os participantes receberam informações quanto à realização e ao objetivo da pesquisa e consentiram na utilização dos dados obtidos. Foram utilizados os questionários de 28, 26 e 23 estudantes do $2^{\circ}$ período de Biologia, Química e Física respectivamente, e 17, 19 e 9 estudantes do $8^{\circ}$ período de Biologia, Química e Física, respectivamente; totalizando 122 graduandos.

\section{c) Questionário}

O instrumento utilizado na pesquisa para obtenção de dados sobre a EI, como citado acima, foi um questionário composto por cinco questões. Quanto à escolha dos tipos de questões, utilizou-se a classificação proposta na literatura estudada (MARCONI \& LAKATOS, 1996; MATTAR, 1996). Segundo essa classificação, as perguntas podem ser: abertas, fechadas (dicotômicas), fechadas (tricotômicas) ou de múltipla escolha. Na elaboração desse questionário, priorizou-se o uso de perguntas abertas e fechadas dicotômicas.

Nas perguntas abertas, as pessoas respondem às questões com suas próprias palavras, ou seja, são questões discursivas. As vantagens desse tipo de perguntas, segundo Mattar, (1996) são: coleta-se uma maior quantidade de informações, os participantes não são influenciados por respostas predeterminadas e são de fácil elaboração. Porém, elas têm as seguintes desvantagens: são de difícil tabulação e análise e podem surgir dificuldades de entendimento como, por exemplo, letra ilegível, erros de ortografia, frases ambíguas e etc. (MATTAR, 1996).

Em questões dicotômicas, a pessoa escolhe a reposta tendo somente duas opções, por exemplo, “sim” ou “não”. Segundo Mattar (1996), dentre as vantagens deste tipo de questão, estão: serem de rápido preenchimento, fácil tabulação e análise dos dados. Como desvantagem pode ser citada a ocorrência de erros sistemáticos. Caso o respondente não concorde com as duas opções de respostas, ele pode optar por uma das alternativas, mesmo não sendo a sua opinião, ou simplesmente não responder à questão.

$\mathrm{Na}$ elaboração do questionário, buscou-se minimizar as desvantagens apresentadas e optar por modalidades de questões mais vantajosas segundo a literatura utilizada.

\section{d) Etapas para Elaboração do Questionário}

Após um estudo bibliográfico inicial, definidos os objetivos da pesquisa, foram determinados os métodos e técnicas de coleta e análise de dados. Nesse momento, o questionário foi escolhido como opção metodológica. Durante o processo de elaboração, os seguintes cuidados foram tomados: verificou-se se a pergunta realizada era importante para a pesquisa (MARCONI \& LAKATOS, 1996), se existia necessidade de mais de uma pergunta sobre o assunto (MATTAR,1996) e se os 
participantes tinham o conhecimento técnico necessário para responder às questões (BOYD \& WETFALL, 1964; MARCONI \& LAKATOS, 1996).

\section{e) Análise Qualitativa e Quantitativa}

Para a análise qualitativa dos dados, foi verificada a existência de uma variedade de técnicas; Mayring (2002) menciona sete maneiras: a) grounded theory, b) análise fenomenológica, c) paráfrase social-hermenêutica, d) análise de conteúdo qualitativa, e) hermenêutica objetiva, f) interpretação psicanalítica de textos e g) análise tipológica. Neste estudo realizamos uma análise qualitativa do conteúdo, sem excluir a quantificação, concordando com Mayring (2002), que enfatiza que a função importante da abordagem qualitativa é a de permitir uma quantificação com propósito.

A análise quantitativa foi realizada por meio de porcentagens, e os dados estatísticos ordenados em gráficos para tornar mais clara a representação dos resultados. A escolha por utilizar tanto análise qualitativa quanto análise quantitativa baseia-se na fundamentação teórico-metodológica apresentada na literatura consultada.

Enquanto participante do processo de construção de conhecimento, idealmente, o pesquisador não deveria escolher entre um método ou outro, mas utilizar as várias abordagens, qualitativas e quantitativas que se adequam à sua questão de pesquisa. (GÜNTHER, 2006, p.207)

\section{RESULTADOS E DISCUSSÃO}

Segundo Claúdia Pereira Dutra, Secretária de Educação Especial do Ministério da Educação, em uma palestra transcrita a respeito dos "Diferentes olhares sobre a inclusão":

Os avanços da educação inclusiva nos últimos anos estão demonstrados nos indicadores do Censo Escolar/INEP. A matrícula de alunos com necessidades educacionais especiais em1996, era de 201.142 alunos, passando em 2004 para 566.753, representando um crescimento de 181\%. A inclusão de alunos em classes comuns do ensino regular, em 1998 era de 13\% em 2004 passa a representar 34,4\% das matrículas. Outro avanço significativo diz respeito à participação da esfera pública, em 1998 eram 6.255 estabelecimentos públicos de ensino e em 2004, são 32.966, representando um crescimento de 427\%. Em 1997, 2.375 municípios apresentavam matrícula de alunos com necessidades educacionais especiais, representando 42,7\%, e em 2004 são 4.273 municípios, perfazendo um total de $77 \%$ dos 5.562 municípios e o Distrito Federal. (DUTRA, 2005, p. 6).

Os dados não só demonstram a urgência na preparação de profissionais que atendam essa demanda, como também informam a existência de um grande número de municípios que já recebem alunos com NEE's.

Após a análise dos dados presentes nos questionários, pode-se observar que tanto estudantes que estão ingressando na universidade quanto os que em 
breve serão egressos, consideram a importância da EI em sua formação, conforme observamos nas respostas a questões como "Você se sente preparado na universidade para lidar com alunos portadores de NEE's?".

Acreditar na possibilidade da inclusão exige posturas diferentes da sociedade e dos estabelecimentos de ensino, além de um currículo e uma escola voltados para o desenvolvimento da competência do aluno e não para seu adestramento cognitivo (REGINATO, 2005). Porém, para que essas transformações se efetivem, são necessárias mudanças na base do processo de ensino, ou seja, na formação inicial de professores.

Quanto à preparação dos educadores para atender esse alunado, Glat e Pletsch (2004) afirmam que:

Essa é uma questão bastante preocupante porque o processo de inclusão escolar (...) está sendo implementado no país, a composição do alunado das escolas se tornando cada vez mais diversificada, e o currículo dos cursos de formação de professores não contempla essa nova realidade. Em conseqüência, os futuros docentes continuarão despreparados para atuar sob novo paradigma da escola aberta à diversidade, resultando em prejuízo social e acadêmico aos alunos incluídos e aos demais agentes participantes. (p. 4-5).

\section{E concluem:}

Para fazer frente a esta realidade as universidades precisam ser capazes de formar dois tipos de educadores: professores do ensino regular que sejam capacitados com um mínimo de conhecimento e prática sobre o alunado diversificado, contemplados nas licenciaturas em geral; e professores "especializados" nas diferentes necessidades educacionais especiais, a nível de especialização ou complementação por meio de habilitações nas faculdades ou departamentos de Educação (p.5).

Apesar do reconhecimento da necessidade urgente de preparar os professores em formação, pouco se tem feito a fim de auxiliá-los enquanto graduandos. Prova disso são os currículos inalterados no que diz respeito à inserção de disciplinas voltadas para o ensino de estudantes com NEE's.a O quadro abaixo mostra algumas das principais Universidades Federais do país assim como a presença de disciplinas de EI nas grades curriculares dos cursos de licenciatura ofertados. A fim de restringir as análises específicas deste estudo, foi verificada apenas a presença de três licenciaturas nas áreas de Ciências exatas e da vida: Biologia, Física e Química. 
Quadro 1: Análise do currículo dos cursos de licenciatura em: Química, Física e Biologia de 16 Universidades

Federais do país. No quadro estão expostas à extrema esquerda as universidades, ao centro as disciplinas relacionadas à inclusão de alunos portadores de NEE's, assim como o curso de graduação que possui tal disciplina e à direita 0 caráter dessas disciplinas (se são obrigatórias ou optativas). Foram analisados somente os currículos das universidades que disponibilizaram as grades curriculares via URLs no período anterior ao envio do artigo para publicação. As fontes para obtenção dos dados do quadro estão após as referências bibliográficas.

\begin{tabular}{|c|c|c|}
\hline $\begin{array}{l}\text { UNIVERSIDADES } \\
\text { FEDERAIS / UF }\end{array}$ & DISCIPLINAS DE INCLUSÃO / CURSO & CARÁTER \\
\hline 1. UNIFAP / Amapá & Não possui & $\ldots$ \\
\hline 2. UFAL / Alagoas & $\begin{array}{l}\text { Libras / Física } \\
\text { Libras / Biologia }\end{array}$ & Obrigatórias \\
\hline 3. UFAM / Amazonas & Não possui & $\ldots$ \\
\hline 4. UFBA / Bahia & Não possui & $\cdots$ \\
\hline 5. UFES / Espírito Santo & Educação e inclusão: Língua Brasileira de Sinais / Química & Obrigatória \\
\hline 6. UFG / Goiás & Não possui & $\cdots$ \\
\hline 7. UFMG / Minas Gerais & Não possui & $\cdots$ \\
\hline $\begin{array}{l}\text { 8. UFMS / Mato- } \\
\text { Grosso do sul }\end{array}$ & $\begin{array}{c}\text { Fundamentos da Educacãão Especial / Física } \\
\text { Educação Especial / Química }\end{array}$ & Obrigatória \\
\hline 9. UFMT / Mato-Grosso & Não possui & $\ldots$ \\
\hline 10. UFPE / Pernambuco & Não possui & $\ldots$ \\
\hline 11. UFPI / Piauí & Não possui & $\cdots$ \\
\hline 12. UFPR / Paraná & Não possui & $\ldots$ \\
\hline $\begin{array}{l}\text { 13. UFRGS / Rio } \\
\text { Grande do Sul }\end{array}$ & $\begin{array}{l}\text { Língua Brasileira de Sinais / Biologia } \\
\text { Intervenção pedagógica e necessidades educativas especiais / Química }\end{array}$ & $\begin{array}{l}\text { Obrigatória } \\
\text { Eletiva }\end{array}$ \\
\hline 14. UFRJ / Rio de Janeiro & Não possui & $\cdots$ \\
\hline 15. UFRR / Roraima & Não possui & $\ldots$ \\
\hline $\begin{array}{l}\text { 16. UFSC / Santa } \\
\text { Catarina }\end{array}$ & $\begin{array}{l}\text { Língua Brasileira de Sinais I / Física } \\
\text { Fundamentos da Educação Especial / Física } \\
\text { Fundamentos da Língua de Sinais Brasileira / Física } \\
\text { Língua Brasileira de Sinais I / Biologia }\end{array}$ & $\begin{array}{l}\text { Obrigatória } \\
\text { Optativa } \\
\text { Optativa } \\
\text { Obrigatória }\end{array}$ \\
\hline
\end{tabular}

Quanto aos atributos necessários ao educador em formação inicial, Pletsch (2009) afirma:

Neste aspecto merece destaque a Proposta de Diretrizes para a Formação de Professores da Educação Básica em Cursos de Nível Superior. No item referente à formação de professores, assinalam-se as competências que devem ser dominadas como parte de um processo permanente de desenvolvimento profissional. Destacam-se aquelas referentes à compreensão do papel social da escola, ao domínio dos conteúdos, à interdisciplinaridade, ao conhecimento dos processos de investigação, ao gerenciamento do próprio desenvolvimento profissional e ao comprometimento com os valores estéticos, políticos e éticos inspiradores da sociedade democrática. (p. 145-146) 
O documento do MEC, acima referido, aponta para uma revisão urgente do processo de formação inicial de professores, de modo a superar problemas em nível institucional e no campo curricular. Nesse sentido, os licenciandos participantes dessa pesquisa foram questionados acerca da relevância da adição de disciplinas de EI em seus currículos específicos. Cerca de $90 \%$ dos estudantes consideraram serem essas disciplinas importantes para sua formação como futuros educadores.

Porém, vale ressaltar que a inserção de uma disciplina no currículo, sem a devida discussão acerca das capacidades e individualidades humanas, pode acabar auxiliando a manutenção de práticas segregacionistas (PLETSCH, 2009). Segundo Bueno:

\begin{abstract}
A inserção de uma disciplina ou a preocupação com conteúdos sobre crianças com necessidades educativas especiais pode redundar em práticas exatamente contrárias aos princípios e fundamentos da educação inclusiva: a distinção abstrata entre crianças que possuam condições para se inserir no ensino regular e as que não as possuam, e a manutenção de uma escola que, através de suas práticas, tem ratificado os processos de exclusão e de marginalização de amplas parcelas da população escolar brasileira (1999, p. 18).
\end{abstract}

Com o objetivo de minimizar a segregação supracitada, Bueno (1999), também sugere que o modelo inclusivo requer a formação de dois tipos de professores:

- "Generalistas", responsáveis pelas classes regulares e capacitados com um mínimo de conhecimento e prática sobre a diversidade do alunado e

- "Especialistas", capacitados na área inclusiva e responsáveis por oferecer o necessário suporte, orientação e capacitação aos professores do ensino regular visando à inclusão.

A proposta de Bueno vem ao encontro do artigo 59 da LDB (Lei de Diretrizes e Bases, 1996) que, conforme indicado no trecho abaixo, reconhece a importância da formação de professores especializados para atender portadores de NEE's:

Os sistemas de ensino assegurarão aos educandos com necessidades especiais:

III - professores com especialização adequada em nível médio ou superior, para atendimento especializado, bem como professores do ensino regular capacitados para a integração [leia-se, inclusão] desses educandos nas classes comuns (p. 156).

Apesar dessas considerações dos estudiosos, a realidade dos graduandos demonstra que poucos deles têm sequer noções de EI. Uma das perguntas do questionário era: "Você sabe o que é Inclusão escolar?". A esse questionamento grande parte dos alunos respondeu afirmativamente, porém poucos explanaram corretamente o significado do termo. Percebe-se assim, que conceitos como o de EI ainda não estão difundidos como deveriam e, devido à falta de compreensão, estes são muitas vezes mal empregados.

A fim de verificar se os graduandos já haviam feito algum curso de curta duração ou mesmo se tinham formação especializada na EI, estes foram questiona- 
dos e os dados obtidos demonstram que menos de 15\% dos futuros professores tem algum curso de curta duração na área. Dessa forma, fica claro que os professores em formação inicial não estão preparados para lidar com um alunado que se tornará cada vez mais evidente e presente nas salas de aula convencionais do ensino regular.

A partir de agora será realizada uma análise individual dos cursos listados, a fim de verificar o posicionamento dos alunos e a visão de cada um dos cursos de Ciências em relação à EI, assim como a variação (se há) entre os estudantes que estão ingressando e aqueles que estão deixando a universidade, de modo a identificar se o curso de formação produziu efeito sobre as opiniões desses licenciandos.

\section{OPINIÃO DOS GRADUANDOS EM BIOLOGIA - LICENCIATURA}

Ao ingressar na universidade, os graduandos em Ciências Biológicas já possuem concepções prévias sobre EI, mesmo que não fundamentadas. Isso porque, $66,7 \%$ dos estudantes do $2^{\circ}$ período afirmaram saber o que é inclusão escolar, mesmo na ausência de disciplinas ou formações complementares. Os graduandos que cursam o $8^{\circ}$ período de Biologia (100\%) também afirmaram conhecer o que é EI. Contudo, as concepções sobre EI de ambos os períodos muitas vezes se apresentaram conflituosas e sem embasamento teórico-prático. Tais considerações podem ser verificadas nas seguintes elocuções dos estudantes ao responder à pergunta sobre o que é EI:

"Incluir no ambiente escolar qualquer tipo de aluno" (E1 - $\left.2^{\circ} \mathrm{P}\right)$;

"Adequação de alunos, com qualquer tipo de necessidade especial no meio escolar" (E2 - $\left.2^{\circ} \mathrm{P}\right)$;

"É a presença de pessoas com deficiências na escola" (E3 - 2P);

"É a postura de aceitação de alunos com necessidades especiais em uma sala de aula convencional" (E4 - 8 P);

"Incluir alunos portadores de necessidades especiais no contexto escolar e no processo de ensino-aprendizagem" (E5 - 8 $\mathrm{P})$.

As afirmações supracitadas indicam que, no $2^{\circ}$ período, a maioria dos estudantes que afirmaram saber o que é EI, explicaram que inclusão é inserir, ter a presença de estudantes portadores de NEE's no ambiente escolar. Em contrapartida, os graduandos do $8^{\circ}$ período afirmaram que EI trata-se da presença dos NEE's no ambiente escolar, porém com sua devida integração (leia-se inclusão) no processo de ensino-aprendizagem, o que demonstra que as discussões no decorrer do curso podem alterar consideravelmente a opinião dos graduandos. Alguns desses graduandos identificam a EI como uma postura, tal como preconiza Arnaiz (1996). Contudo, a EI ainda é vista de modo superficial pelos professores em formação inicial, visto que nenhum deles mencionou fatores primordiais como: a reestruturação político-pedagógica, a adequação do currículo e da estrutura física, equipe docente e demais funcionários das escolas. 
Vale ressaltar que os licenciandos de Biologia do $2^{\circ}$ período $(95,83 \%)$ e do $8^{\circ}$ período $(100 \%)$ não se sentem capacitados pela universidade para ensinar conhecimentos científicos aos alunos portadores de NEE's. Esses dados são confirmados pelas afirmações dos estudantes:

"Não, pois ainda não obtive nenhum contato" (E6 - $\left.2^{\circ} \mathrm{P}\right)$;

"Não, pois a universidade não nos prepara para isso" (E7 - $\left.2^{\circ} \mathrm{P}\right)$;

"Não. As discussões em disciplinas são inadequadas ou inexistentes e os estágios não abordam a inclusão escolar" (E8 - 8 P);

"Não muito. Alguns portadores de necessidades especiais precisam de certos cuidados que eu não sou capacitado, por exemplo, a linguagem de sinais" (E9 - 8P);

Os mesmos graduandos ainda afirmam que as disciplinas de EI seriam relevantes em seu processo de formação (95,83\% para o $2^{\circ}$ período e $88,9 \%$ para o $8^{\circ}$ período). Apenas um estudante do $2^{\circ}$ período disse que é necessário um programa de EI, ao invés de apenas algumas disciplinas. Nesse sentido, o presente trabalho indica que a inclusão de disciplinas (obrigatórias e/ou optativas) no currículo da licenciatura em Biologia seria bem aceito pelos graduandos e possibilitaria uma formação inicial em EI efetivamente significativa. Cabe destacar que as disciplinas possibilitariam a formação de professores generalistas e caso houvesse um programa mais elaborado, a formação de especialistas.

A importância de disciplinas sobre EI no currículo dos graduandos baseia-se no fato de que poucos licenciandos em Biologia (4,2\% para o $2^{\circ}$ período e $10,1 \%$ para o $8^{\circ}$ período) possuem formação complementar, tais como cursos de curta duração, oficinas e/ou palestras, sobre EI.

O instituto de Ciências Biológicas da Universidade Federal de Goiás conta com um Núcleo de Estudos em Tecnologias para Socialização do conhecimento em Biologia - NETESB, que dentre suas inúmeras atividades de extensão também oferta cursos de curta duração com ênfase na promoção da EI, como o curso de Braille. Porém, o Núcleo conta com um espaço limitado e poucos recursos, o que dificulta a disponibilização de vagas que atendam grande parte dos graduandos.

\section{OPINIÃO DOS GRADUANDOS EM FÍSICA - LICENCIATURA}

No caso dos graduandos em Física, constatou-se que grande parte dos mesmos tem dificuldade para definir Inclusão escolar. Ao questionarmos os estudantes que cursam o $2^{\circ}$ período do curso acerca da EI, 60\% afirmaram não saber explicar a definição, e os demais 40\% responderam de forma incompleta. Alguns estudantes afirmaram que a EI:

"É a inserção de pessoas com necessidades especiais nas escolas regulares" (E1 - 20P);

"É inserir alunos com necessidades especiais nas escolas para alunos normais" (E2 - 2P). 
A partir de respostas como as mostradas acima verificou-se que muitos estudantes recém ingressos no curso de Física consideraram que a EI corresponde apenas à inserção dos alunos portadores de NEE's em escolas regulares. Essa definição é questionada por Padilha (2004), que afirma que juntar crianças em uma sala de aula não lhes garante ensino e principalmente não lhes garante aprendizagem.

Segundo Bueno (1999), a inclusão escolar vai desde o direito de acesso e permanência dos alunos portadores de NEEs nas escolas regulares até a modificação de toda a estrutura física e a organização pedagógica da escola para receber e incluir esse alunado. Dessa forma, EI é reconhecer as inúmeras diferenças existentes (pessoais, linguísticas, culturais, sociais etc.) e mudar o sistema educacional de forma a atender a toda diversidade.

Ao analisar as respostas dos estudantes que cursavam o semestre final do curso, $8^{\circ}$ período, percebeu-se que $91 \%$ destes afirmaram saber o que é a EI. Apesar disso, constatou-se que somente $36 \%$ dos estudantes a explicaram de forma completa. Dessa forma, pode-se perceber que mesmo com um percentual maior de licenciandos afirmando saber o que é EI, poucos efetivamente sabem seu real significado. Nesse caso, os alunos do $8^{\circ}$ período mostraram a mesma visão dos graduandos do $2^{\circ}$ período, para os quais a EI corresponde somente à união dos estudantes normóticos e portadores de NEEs em um mesmo ambiente de ensino:

"Trata-se do direito que os alunos deficientes têm de receber educação formal em espaços oficiais de ensino, juntamente com alunos normóticos" (E3 - 8P);

"É quando alunos com necessidades especiais são colocados junto com outros alunos que não possuem necessidades especiais” (E4 - 8P).

Essa visão superficial dos estudantes do curso de Física acerca da EI pode ser justificada devido à não existência de disciplinas obrigatórias na grade curricular que dão instruções acerca de Inclusão Educacional.

No entanto, alguns estudantes do $8^{\circ}$ período explicaram o conceito de EI de forma menos superficial, o que demonstra a aquisição de novas posturas e reflexões no decorrer do curso, ainda que não desenvolvidas numa disciplina específica. Nesse sentido, embora ainda longe do ideal, os graduandos do $8^{\circ}$ período se aproximaram mais da definição proposta por Bueno (1999) e responderam que a EI:

"É proporcionar a participação nas atividades escolares a todos os estudantes, mesmos com diferenças físicas, sociais, etc. A escola deve adaptar suas atividades de modo que todos possam participar" (E5 - 8P);

É a adequação das aulas e das escolas frente a alunos com necessidades especiais (E6 - 8P).

O percentual de $85 \%$ dos estudantes do $2^{\circ}$ período do curso de Física e $83 \%$ dos graduandos do último semestre, disseram não se sentirem preparados para lidar com alunos portadores de NEE's. Ao questionamento sobre a possibilidade de, no futuro, terem que lidar com alunos portadores de NEE's, muitos afirmaram que: 
"Não há nenhuma orientação no curso de licenciatura em física sobre inclusão escolar" (E7 - 2 P);

"Tudo que aplicaria em sala de aula com esses alunos seriam métodos comuns" (E8 - 8P).

A dificuldade enfrentada pelos estudantes para falar sobre EI e as afirmações acerca do receio dos estudantes em ter que lidar com portadores de NEE's vem da falta de preparo dos licenciandos nas instituições de ensino superior. Verificou-se que $100 \%$ dos estudantes do $2^{\circ}$ período do curso e $83 \%$ dos estudantes do $8^{\circ}$ período nunca tiveram uma formação especializada na área. Mas $90 \%$ dos licenciandos do $2^{\circ}$ período e $100 \%$ do $8^{\circ}$ período consideraram que disciplinas de inclusão educacional no currículo seriam relevantes para a sua formação:

"Para aprendermos como lidar com alunos com NEEs estas disciplinas seriam importantíssimas" (E9 - $\left.2^{\circ} \mathrm{P}\right)$.

"Seria de grande importância, pois enriqueceria todos os métodos de prática de ensino que já vimos no decorrer do curso e nos tornaria profissionais mais capacitados" (E10 - 8P).

Os resultados da presente pesquisa apontam que os licenciandos do curso de Física tornam-se egressos da Universidade sem uma formação específica para lidar com a EI no ensino básico. Segundo Marques (2000, p.10), a Educação Inclusiva enfrenta dificuldades para ser estabelecida principalmente devido a esse despreparo dos docentes e de toda a comunidade escolar para acolher os portadores de NEE's.

A figura do professor aparece então como a base de qualquer tentativa de construção da inclusão escolar, uma vez que ele executa a prática pedagógica, sendo um sujeito importante no sistema educacional. Como pode ser constatado ao investigar o curso de formação de professores de Física da UFG, não ocorre a formação profissional do educador inclusivo.

\section{OPINIÃO DOS GRADUANDOS EM QUÍMICA - LICENCIATURA}

No que diz respeito aos graduandos do curso de Química, constatou-se que, dos estudantes do $2^{\circ}$ período, $50 \%$ não sabem o que é EI, porém dos $50 \%$ restantes que afirmaram saber o que é EI, poucos deram respostas coerentes e válidas. Fato semelhante pode ser observado nas respostas dos graduandos do $8^{\circ}$ período, em que 73,3\% afirmaram não saber o que é EI.

Alguns estudantes de ambos os períodos afirmaram que EI seria uma forma de trazer portadores de NEE's, negros e pessoas de baixa renda para o ambiente escolar. É fato que a inclusão social e a inclusão educacional estão, de certa forma, essencialmente entrelaçadas, porém em diversos aspectos devem ser consideradas isoladamente, principalmente no que diz respeito aos projetos de execução.

Alguns estudantes utilizaram o termo "diferente" para se referir aos portadores de NEE's; quanto a isso Rodrigues (2006, p. 5), afirma que:: 
Frequentemente o termo "diferente" é usado como um "alter nomine" de "deficiente" (sinalização de um qualquer problema num aluno). Tal como no período integrativo existiam os "deficientes" e os "normais" encontramos agora os "diferentes" e os "normais". Mas o que é afinal ser diferente? E diferente de quê? (...) Sabemos que não são só diferentes os alunos com uma condição de deficiência: muitos outros alunos sem condição de deficiência identificada não aprendem se não tiverem uma atenção particular ao seu processo de aprendizagem.

Heward (2003) afirma que todos os alunos são diferentes, porém isso não implica que cada um tenha que aprender segundo uma metodologia diferente; significa, no entanto, que se não forem proporcionadas abordagens diferentes ao processo de aprendizagem, cria-se a desigualdade para muitos alunos. Ser diferente não é um atributo negativo, e não deve ser tomado como tal. É, antes de tudo, uma característica essencialmente humana. Ninguém é igual a ninguém.

Quanto ao preparo que recebem na universidade para lidar futuramente com portadores de NEE's $72,2 \%$ e $93,3 \%$ dos estudantes do $2^{\circ}$ e $8^{\circ}$ períodos, respectivamente, afirmaram não se sentir preparados:

"Me sinto despreparado para lidar com tal situação" (E1 - 2P)

"Não me sinto preparado, pois a universidade não me deu suporte para isso, há uma dificuldade maior com os conteúdos de química, pois a química é uma ciência que lida muito com a abstração." (E2 - 8P)

Esse fato reforça a necessidade urgente de melhores propostas de ensino e de divulgação de metodologias para facilitar o processo de ensino/aprendizagem para portadores de NEE's.

Cerca de $90 \%$ dos graduandos do $2^{\circ}$ período e $80 \%$ do $8^{\circ}$ período não têm curso de formação específica para EI. Apesar do interesse dos estudantes e de considerarem a importância de uma formação especializada na área, poucos deles têm um curso de curta ou longa duração em EI, ou seja, mesmo que a universidade não ofereça em sua grade, poucos deles tiveram a oportunidade ou mesmo o desejo de procurar cursos nessa área.

A comparação entre os períodos dos cursos de licenciatura supracitados nos permitiu verificar que há uma variação, ainda que pequena, nas opiniões dos estudantes, de modo que, no $8^{\circ}$ período, os graduandos demonstraram mais conhecimento a respeito da definição e da importância da EI para sua formação, do que os estudantes do $2^{\circ}$ período. Isso pode se justificar pelo fato de aqueles já terem passado pelos estágios, momentos de reflexão sobre a prática em que o estudante pode observar a realidade que o espera ao ingressar no mercado de trabalho.

Durante os estágios de regência, alguns professores em formação inicial têm a oportunidade de lidar com estudantes com NEE's, fato que pode estimular a leitura e a busca de novas metodologias para facilitar o processo de ensino-aprendizagem do alunado e, dessa forma, proporcionar ao educador algum conhecimento nesse sentido. 
Além disso, alguns professores na academia também têm interesse nessas áreas e reconhecem sua relevância na formação inicial, promovendo debates, fornecendo textos e incentivando a discussão a respeito da EI, porém, ainda que esses debates sejam realizados nos períodos iniciais, percebe-se que os estudantes, em geral, não possuem elementos ou mesmo vivência que os permita analisar, participar e apreender os elementos fornecidos nessas discussões.

\section{CONCLUSÕES}

As mudanças históricas, sócio-culturais e econômicas da sociedade atual têm promovido mudanças nos paradigmas educacionais, em especial quanto à inclusão de estudantes portadores de NEE's nas escolas regulares. Entende-se que a inclusão não deve se limitar apenas à presença dos portadores de NEE's no ambiente escolar, mas principalmente refletir mudanças no comportamento e na posição dos participantes do processo de ensino-aprendizagem. Sendo assim, a EI envolve tanto o direito de acesso e permanência dos estudantes portadores de NEEs nas escolas regulares quanto a modificação de toda a estrutura física e organização pedagógica para receber e incluir esse alunado.

O presente estudo permitiu-nos verificar que há uma carência, nos cursos de licenciatura em Biologia, Física e Química, em relação ao conhecimento sobre a EI de alunos portadores de NEE's. Portanto, é de grande relevância a discussão acerca da EI durante a formação inicial, a fim de que os graduandos possam ser capacitados para lidar, num futuro não muito distante, com estudantes portadores de NEE's, auxiliando-os para que sejam tão ativos no currículo, nas políticas e práticas educacionais quanto qualquer outro estudante. Afinal, como afirma Santos (1999), todos temos direito à igualdade quando a diferença nos inferioriza e direito à diferença quando a igualdade nos descaracteriza.

\section{REFERÊNCIAS BIBLIOGRÁFICAS}

ARNAIZ, Sánchez P. (1996). Las escuelas son para todos. Siglo Cero, v. 27, n. 2, p. 25-34.

AINSCOW, M. Desarrollo de escuelas inclusivas. Ideas, propuestas y experiencias para mejorar las instituciones escolares. Madrid: Narcea. 2001.

BOYD, H. W. J.; WETFALL, R. Pesquisa mercadológica: texto e caso. Rio de Janeiro: Fundação Getúlio Vargas, 1964. BUENO, J. G. Crianças com necessidades educativas especiais, política educacional e a formação de professores: generalistas ou especialistas. Revista Brasileira de Educação Especial, v. 3. n.5, p. 7-25, 1999. BUENO, J. G. Educação inclusiva: princípios e desafios. Revista Mediação, n. 1, p. 22-28, 1999.

BUENO, J. G. A inclusão de alunos diferentes nas classes comuns do ensino regular. In: Temas sobre Desenvolvimento. São Paulo, v. 9, n. 54, p. 21-27, 2001.

BRASIL. Lei de Diretrizes e Bases da Educação Nacional - LDB (Lei n.o 9394/96). 20 de dezembro de 1996. Disponível em: http://www.oei.es/quipu/brasil/educ_especial.pdf. Acesso em: 29/04/2010. CASTANHO, D. M.; FREITAS S. N. Inclusão e prática docente no ensino superior. In: Revista Educação Especial. Santa Maria, n. 27, 2005. Disponível em: http:// www.ufsm.br/ce/revista/ceesp/2006/01/a6.htm. Acesso em: 29 de Nov de 2009. 
CAVALCANTE, R. S. C. A inclusão do aluno com necessidades educacionais especiais na sala de aula de ensino regular: o papel do professor. Temas sobre Desenvolvimento, v.9, n.52, p.31-5, 2000.

CROKER, A.; KENTISH, M. Serviços de fisioterapia para crianças em idade pré escolar e escolar. In: BURNS, Y. R.; MACDONALD, J. Fisioterapia e crescimento na infância. São Paulo: Santos, 1999.

D’ANTINO, M. E. F. A Questão da Integração do Aluno com Deficiência Mental na Escola Regular. In: MANTOAN, M. T. E. A Integração de Pessoas com Deficiência. São Paulo: Memnon/SENAC, 1997. DUTRA, C. P. Diferentes olhares sobre a inclusão. Palestra da reunião do CONADE. 2005. In: www. mj.gov.br/conade/arquivos/.../palestras_DiferentesOlhares.doc. Acesso em: 19/08/2009.

FERREIRA, J. R. e GLAT, R. Reformas educacionais pós-LDB: a inclusão do aluno com necessidades especiais no contexto da municipalização. In: Souza, D. B. \& Faria, L. C. M. (Orgs .) Descentralização, municipalização e financiamento da Educação no Brasil pós-LDB. Rio de Janeiro: DP\&A, 2003.

FIGUEIREDO, R. V. Políticas de inclusão: escola-gestão da aprendizagem na diversidade. In: ROSA, D. E. G.; SOUZA, V. C. (orgs). Politicas organizativas e curriculares, educação inclusiva e formaşão de professores. Rio de Janeiro: DP\&A, 2002.

GLAT, R. Capacitação de professores: pré-requisito para uma escola aberta à diversidade. Revista Souza Marques, v. 1, p. 16-23, 2000.

GLAT, R., FERREIRA, J. R., OLIVEIRA, E. S. G. \& SENNA, L. A. Panorama nacional da educação inclusiva no Brasil. Relatório de consultoria técnica, projeto Educação Inclusiva no Brasil. Banco Mundial, 2003, disponível em: www.cnotinfor.pt/projectos/worldbank/inclusiva/entrada.pt.html, acessado em nov./2003. GÜNTHER, H. Pesquisa Qualitativa Versus Pesquisa Quantitativa: Esta É a Questão?. Psicologia: Teoria e Pesquisa, Brasilia. v. 22, n. 2, p. 201-210. 2006.

MANTOAN, M. T. E. Produção de conhecimentos para a abertura das escolas às diferenças: a contribuição do LEPED (Unicamp), 2002. Disponível em: http://www.bancodeescola.com/cenario. htm. Acesso em: 29/04/2010.

MARCONI, M. D. A.; LAKATOS, E. M. Técnicas de pesquisa: planejamento e execução de pesquisas, amostragens e técnicas de pesquisas, elaboração, análise e interpretação de dados. 3.ed. São Paulo: Atlas, 1996. MATTAR, F. N. Pesquisa de marketing: edição compacta. São Paulo: Atlas, 1996.

MAYRING, PH. Einfübrung in die qualitative Sozialforschung. Introdução à pesquisa social qualitativa. (5 ed.). Weinheim: Beltz. 2002.

NÓVOA, A. Formação de professores e profissão docente. In: . Os Professores e a sua formação. Lisboa: Nova Enciclopédia, publicações Dom Quixote, 1992. (Coleção Temas de Educação, 39). PADILHA, A. M. O que fazer para não excluir Davi, Hilda, Diogo... In: GÓES, M. C. R.; LAPLANE, A.L. F. (orgs.). Políticas e práticas de educação inclusiva. Campinas: Autores Associados, 2004. PERRENOUD, P. Pedagogia Diferenciada: das intenções à ação. Porto Alegre: Artmed. 2000.

PLETSCH, M. D. A formação de professores para a educação inclusiva: legislação, diretrizes políticas e resultados de pesquisas. Educ. rev., Curitiba, n. 33, 2009 . Disponível em: <http://www.scielo.br/scielo.php?script $=$ sci_arttext\&pid $=\mathrm{S} 010440602009000100010 \& \operatorname{lng}=\mathrm{en} \& \mathrm{nrm}=\mathrm{iso}>$. Acesso em 10 Nov. 2009. doi: 10.1590/S0104-40602009000100010.

REGINNATO, L. G. Inclusão escolar do deficiente físico: a visão dos profissionais de escolas municipais e de fisioterapeutas atuantes na área de neuropediatria do município de Cascavel. Monografias do Curso de Fisioterapia da Unioeste. Cascavel - PR, n. 01 - 2005 ISSN 1675-8265.

RODRIGUES, D. (org). Inclusão e Educação: doze olhares sobre a Educação Inclusiva, S. Paulo. Summus Editorial. 2006.

SACRISTÁN, J. G. Poderes Instáveis em Educação. Porto Alegre, Artes Médicas, 1999.

SANTOS, B. de S. A construção multicultural da igualdade e da diferença. Coimbra: Centro de Estudos Sociais. Oficina do CES no 135, 1999.

SANTOS, L. L. C. P. Dimensões pedagógicas e políticas da formação contínua. In: VEIGA (org.) Caminhos da profissionalização do magistério. Campinas: Papirus. 1998.

SILVA, A. I. T.; SILVA, D.B.R.; AGNELLI, L.B.; HIGUCHI, M.A.; OLIVEIRA, M.C.; SILVA, P.C.; MANCINI, M.C.; VARELA, R.C.B. Perfil funcional de crianças com paralisia cerebral na escola regular segundo tipo de escola e comprometimento motor. Temas sobre Desenvolvimento, v.13, n.74, p. 5-13, 2004. 
Educação Inclusiva e a Formação de Professores de Ciências: o papel

das universidades federais na capacitação dos futuros educadores

UNESCO, MEC-Espanha. Declaração de Salamanca e linha de ação. Brasília: CORDE, 1994.

Fontes utilizadas para obtenção das grades curriculares dos cursos de Biologia, Química e Física - Licenciatura para construção do quadro das Universidades Federais.

Amapá:

Grade curricular do curso de Biologia Licenciatura da Universidade Federal do Amapá. Disponível em: http://www2.unifap.br/biologia/grade-curricular/licenciatura/. Acesso em: 19/02/2010.

Grade curricular do curso de Física Licenciatura da Universidade Federal do Amapá. Disponível em: http://www2.unifap.br/fisica/graduacao/matriz-curricular/. Acesso em: 19/02/2010.

\section{Alagoas:}

Grade curricular do curso de Biologia Licenciatura da Universidade Federal de Alagoas. Disponível em: http://www.ufal.edu.br/ufal/ensino/graduacao/cursos/campus-maceio/ppc-biologia-licenciatura.pdf. Acesso em 11/07/2010.

Grade curricular do curso de Física Licenciatura da Universidade Federal de Alagoas. Disponível em:http://www.ufal.edu.br/ufal/ensino/graduacao/cursos/campus-maceio/ppc-fisica-licenciatura.pdf. Acesso em: 11/07/2010.

Grade curricular do curso de Química Licenciatura da Universidade Federal de Alagoas. Disponível em: http://www.iqb.ufal.br/ggraduacao/ofertaslicenciaturaanual.htm. Acesso em: 11/07/2010.

\section{Amazonas:}

Grade curricular do curso de Química Licenciatura da Universidade Federal do Amazonas. Disponível em: http://www.comvest.ufam.edu.br/quimica_diurno.htm. Acesso em: 23/02/2010.

Grade curricular do curso de Licenciatura em Ciências Naturais da Universidade Federal do Amazonas. Disponível em: http://www.comvest.ufam.edu.br/ciencias.htm. Acesso em: 23/02/2010.

Grade curricular do curso de Física Licenciatura da Universidade Federal do Amazonas. Disponível em: http://www.comvest.ufam.edu.br/fisica_diurno.htm. Acesso em: 23/02/2010.

\section{Babia:}

Grade curricular do curso de Biologia Licenciatura da Universidade Federal da Bahia. Disponível em: http://www.biologia.ufba.br/docs/grade_curricular_08/discip_fluxo_licenciatura_2008-1.pdf Acesso em: 23/02/2010.

Grade curricular do curso de Física Licenciatura da Universidade Federal da Bahia. Disponível em:http://www.colgrad.fis.ufba.br/ Acesso em: 23/02/2010.

Grade curricular do curso de Química Licenciatura da Universidade Federal da Bahia. Disponível em: http://www.supac.ufba.br/Grade_Curricular/Area_I/126120\%20QUIMICA_CES_Licenciatura.pdf Acesso em: 23/02/2010.

\section{Espirito Santo:}

Grade curricular do curso de Biologia Licenciatura da Universidade Federal do Espírito Santo. Disponível em: http://www.prograd.ufes.br/cursos_de_graduacao/grades_curriculares/grade_ciencias_biologicas_2006.pdf Acesso em: 23/02/2010.

Grade curricular do curso de Física Licenciatura da Universidade Federal do Espírito Santo. Disponível em:http://www.prograd.ufes.br/cursos_de_graduacao/grades_curriculares/grade_fisica_2008. pdf. Acesso em: 23/02/2010.

Grade curricular do curso de Química Licenciatura da Universidade Federal do Espírito Santo. Disponível em: http://www.prograd.ufes.br/cursos_de_graduacao/grades_curriculares/grade_quimica_2006.pdf. Acesso em: 23/02/2010.

\section{Minas Gerais:}

Grade curricular do curso de Biologia Licenciatura da Universidade Federal de Minas Gerais Disponível em: http://www.icb.ufmg.br/icb/images/stories/files/grade_curricular_biologia_diurno.pdf 
Acesso em: 23/02/2010.

Grade curricular do curso de Física Licenciatura da Universidade Federal Minas Gerais. Disponível em: http://www.fisica.ufmg.br/graduac/ Acesso em: 23/02/2010.

Grade curricular do curso de Química Licenciatura da Universidade Federal Minas Gerais. Disponível em: http://www.qui.ufmg.br/assets/docs/quimica/matricula/diurno_2_2009.pdf Acesso em: $23 / 02 / 2010$

Mato Grosso do Sul:

Grade curricular do curso de Biologia Licenciatura da Universidade Federal do Mato Grosso do Sul. Disponível em: http://www.sien.ufms.br/cursos/grade/0101. Acesso em: 23/02/2010.

Grade curricular do curso de Física Licenciatura da Universidade Federal do Mato Grosso do Sul. Disponível em: http://www.sien.ufms.br/cursos/grade/0215. Acesso em: 23/02/2010.

Grade curricular do curso de Química Licenciatura da Universidade Federal do Mato Grosso do Sul. Disponível em: http://www.sien.ufms.br/cursos/grade/0217. Acesso em: 23/02/2010.

\section{Mato-Grosso:}

Grade curricular do curso de Biologia Licenciatura da Universidade Federal do Mato Grosso. Disponível em: http://www.ufmt.br/institucional/proreitoria/proeg/cursos_oferecidos_campus/pdf/ cuiaba-pdf/Biologia.pdf. Acesso em 11/07/2010.

Grade curricular do curso de Química Licenciatura da Universidade Federal do Mato Grosso. Disponível em: http://www.ufmt.br/institucional/proreitoria/proeg/cursos_oferecidos_campus/pdf/ cuiaba-pdf/Quimica_Licenciatura.pdf. Acesso em 11/07/2010.

Grade curricular do curso de Física Licenciatura da Universidade Federal do Mato Grosso. Disponível em: http://www.proeg.ufmt.br/cursos/menu_fisica_050404.htm. Acesso em 11/07/2010.

\section{Paraná:}

Grade curricular do curso de Biologia Licenciatura da Universidade Federal do Paraná. Disponível em: http://www.bio.ufpr.br/graduacao/cienciasbiologicas/index.htm Acesso em: 16/03/2010.

Grade curricular do curso de Física Licenciatura da Universidade Federal do Paraná. Disponível em: http://fisica.ufpr.br/grad/ Acesso em: 16/03/2010.

Grade curricular do curso de Química Licenciatura da Universidade Federal do Paraná. Disponível em: http://www.quimica.ufpr.br/cqui/Ajuste_Curricular_Quimica_2008_Proposta_Resolucao_20122008.pdf Acesso em: 16/03/2010.

\section{Pernambuco:}

Grade curricular do curso de Química Licenciatura da Universidade Federal do Pernambuco. Disponível em: http://www.proacad.ufpe.br/cursos/perfis_08/quimica_licenciatura_perfil_5007.pdf Acesso em: 24/02/2010.

Grade curricular do curso de Física Licenciatura da Universidade Federal do Pernambuco. Disponível em: http://www.proacad.ufpe.br/cursos/perfis_08/fisica_licenciatura_perfil_4605.pdf. Acesso em: 24/02/2010.

Grade curricular do curso de Biologia Licenciatura da Universidade Federal do Pernambuco. Disponível em: http://www.proacad.ufpe.br/cursos/perfis_08/ciencias_biologicas_licenciatura_perfil_5502.pdf. Acesso em: 24/02/2010.

\section{Piani:}

Grade curricular do curso de Biologia Licenciatura da Universidade Federal do Piauí. Disponível em: http://www.ufpi.br/ccn/cursos.php?cid=15 Acesso em 11/07/2010.

Grade curricular do curso de Física Licenciatura da Universidade Federal do Piauí. Disponível em: http://www.ufpi.br/ccn/cursos.php?cid=11 Acesso em 11/07/2010.

Grade curricular do curso de Química Licenciatura da Universidade Federal do Piauí. Disponível 
Educação Inclusiva e a Formação de Professores de Ciências: o papel

das universidades federais na capacitação dos futuros educadores

em: http://www.uapi.ufpi.br/quimica/arquivos/file/Microsoft $\% 20$ Word\%20-\%20Projeto_EAD_ QUIMICA_21-09_09[Fluxo\%20Cor].pdf. Acesso em 11/07/2010.

Rio Grande do Sul:

Grade curricular do curso de Biologia Licenciatura da Universidade Federal do Rio Grande do Sul. Disponível em: http://www1.ufrgs.br/graduacao/xInformacoesAcademicas/curriculo.php?CodCu rso $=307 \&$ CodHabilitacao $=94 \&$ CodCurriculo $=267 \&$ sem $=2009022$. Acesso em: 16/03/2010.

Grade curricular do curso de Física Licenciatura da Universidade Federal do Rio Grande do Sul. Disponível em: http://www1.ufrgs.br/graduacao/xInformacoesAcademicas/curriculo.php?CodCu rso $=330 \&$ CodHabilitacao $=102 \&$ CodCurriculo $=288 \&$ sem $=2011012$. Acesso em: 16/03/2010.

Grade curricular do curso de Química Licenciatura da Universidade Federal do Rio Grande do Sul. Disponível em: http://www1.ufrgs.br/graduacao/xInformacoesAcademicas/curriculo.php?CodCu $\mathrm{rso}=343 \&$ CodHabilitacao $=115 \&$ CodCurriculo $=324 \& s e m=2009022$. Acesso em: 16/03/2010.

Rio de Janeiro:

Grade curricular do curso de Biologia Licenciatura da Universidade Federal do Rio de Janeiro. Disponível em: https://www.siga.ufrj.br/sira/temas/zire/frameConsultas.jsp?mainPage=/repositoriocurriculo/FC6143BD-92A4-F79D-41E5-7318CB2D6473.html. Acesso em: 16/03/2010.

Grade curricular do curso de Física Licenciatura da Universidade Federal do Rio de Janeiro. Disponível em: https://www.siga.ufrj.br/sira/temas/zire/frameConsultas.jsp?mainPage=/repositoriocurriculo/0E3DEFEC-92A4-F716-0184-9C5C38D52DB6.html. Acesso em: 16/03/2010.

Grade curricular do curso de Química Licenciatura da Universidade Federal do Rio de Janeiro. Disponível em: https://www.siga.ufrj.br/sira/temas/zire/frameConsultas.jsp?mainPage=/repositoriocurriculo/CEBA6BFB-92A4-F7A0-308E-BB1CD95624FE.html. Acesso em: 16/03/2010.

\section{Roraima:}

Grade curricular do curso de Física Licenciatura da Universidade Federal de Roraima. Disponível em: http://www.ufrr.br/prg/grades/LICENCIATURA_FISICA_(CURRICULO_NOVO).pdf Acesso em: 16/03/2010.

Grade curricular do curso de Biologia Licenciatura da Universidade Federal de Roraima. Disponível em: http://www.ufrr.br/prg/grades/LICENCIATURA_CIENCIAS_BIOLOGICAS.pdf Acesso em: 16/03/2010.

\section{Santa Catarina:}

Grade curricular do curso de Física Licenciatura da Universidade Federal de Santa Catarina. Disponível em: http://notes.ufsc.br/aplic/curGrad.nsf/27985f7d0220152b8525639200750d4d/eea1e70b8 ac533cb03256e1600596cf5/\$FILE/FÍSICA\%20-\%20Licenciatura\%20(noturno) $\% 20$ [curriculo\%20 19941].pdf Acesso em: 16/03/2010.

Grade curricular do curso de Biologia Licenciatura da Universidade Federal de Santa Catarina. Disponível em: http://notes.ufsc.br/aplic/curGrad.nsf/27985f7d0220152b8525639200750d4d/eda59 1908fd47b5483256e140062200f/\$FILE/CIÊNCIAS\%20BIOLÓGICAS\%20[curriculo\%2020061]. pdf Acesso em: 16/03/2010.

Grade curricular do curso de Químicaa Licenciatura da Universidade Federal de Santa Catarina. Disponível em: http://notes.ufsc.br/aplic/curGrad.nsf/27985f7d0220152b8525639200750d4d/e9 7ca7bbb9fde42803256e16005632f7/\$FILE/QUÍMICA.pdf Acesso em: 16/03/2010.

Data de Recebimento: 06/02/2011

Data de Aprovação: 04/07/2011

Data da Versão Final: 26/10/2011 
